\title{
Quasi static analysis of a biocomposite aircraft radome
}

\begin{abstract}
This paper investigates the quasi static compression analysis behavior of a biocomposite radome using nonlinear static modeling. Bio-based fiber is proposed to be used in aircraft radome due to its low dielectric constant. In this instance, kenaf was being utilized as the natural fiber to form a hybrid combination of fiberglass/kenaf epoxy laminates. The quasi static behavior was modeled using MDNastran SOL106 Nonlinear Static. The radome was modeled as a hemispherical shell based on Beechcraftôs radome geometric configuration. The radome is designed as a four-layered laminates with randomly oriented fiberglass and kenaf. The nonlinear compression was performed in the range of $0.01 \mathrm{~mm}$ to $0.49 \mathrm{~mm}$ with a maximum reaction force of $189 \mathrm{~N}$. The radome was not displaced equally or symmetrically as the translational load applied since the shape of radome is asymmetry and the surface at the top is uneven. The increment of the forces leads to elastic local flattening deformation at the apex of the radome. Its shape influences in determining the displacement and the stress to the radome.
\end{abstract}

Keyword: Kenaf; Nonlinear static analysis; Quasi static; Radome 